\title{
Influence of the contact metal on the performance of $n$-type carbonyl-functionalized quaterthiophene organic thin-film transistors
}

\author{
S. Schols, ${ }^{1, a), b)}$ L. Van Willigenburg, ${ }^{1, c)}$ R. Müller, ${ }^{1}$ D. Bode, ${ }^{1, a)}$ M. Debucquoy, ${ }^{1, a)}$ \\ S. De Jonge, ${ }^{1}$ J. Genoe, ${ }^{1}$ P. Heremans, ${ }^{1, a)}$ S. Lu, ${ }^{2}$ and A. Facchetti ${ }^{2, d}$ \\ ${ }^{1} I M E C$ v.z.w., SOLO/PME, Kapeldreef 75, B-3001 Leuven, Belgium \\ ${ }^{2}$ Polyera Corporation, 8025 Lamon Avenue, Skokie, Illinois 60077, USA
}

(Received 18 July 2008; accepted 9 December 2008; published online 30 December 2008)

\begin{abstract}
Organic thin-film transistors using 5, 5'"'-diperfluorohexylcarbonyl-2, $2^{\prime}: 5^{\prime}, 2^{\prime \prime}: 5^{\prime \prime}, 2^{\prime \prime \prime}$ quaterthiophene (DFHCO-4T) as the electron conducting organic semiconductor are fabricated and the performance of these transistors with different top-contact metals is investigated. Transistors with $\mathrm{Au}$ source-drain top contacts attain an apparent saturation mobility of $4.6 \mathrm{~cm}^{2} / \mathrm{V} \mathrm{s}$, whereas this parameter is 100 times lower for similar transistors with $\mathrm{Al} / \mathrm{LiF}$ top contacts. We explain this lower performance by the formation of a thin interfacial layer with poor charge injection properties resulting from a redox reaction between $\mathrm{Al}$ and DFHCO-4T. (C) 2008 American Institute of Physics. [DOI: $10.1063 / 1.3059556]$
\end{abstract}

Driven by potential applications of complementary logic, the field of electron-channel ( $n$-type) organic thin-film transistors $(n$-OTFT) and corresponding $n$-type materials has recently gained a lot of attention. Examples of such materials are fullerene, ${ }^{1}$ naphthalene, ${ }^{2}$ perylene, ${ }^{3}$ and oligothiophene ${ }^{4}$ derivatives. Recently, 5, 5"'-diperfluorohexylcarbonyl$2,2^{\prime}: 5^{\prime}, 2^{\prime \prime}: 5^{\prime \prime}, 2^{\prime \prime \prime}$-quaterthiophene (DFHCO-4T) (Fig. 1) was shown to have an electron field-effect mobility of $1.7 \mathrm{~cm}^{2} / \mathrm{V} \mathrm{s} .^{5}$ Top-contact geometry Au source and drain contacts were used in these devices. In the present letter, we compare the performance of DFHCO-4T transistors with different top-contact metals. While most $n$-OTFTs show good performance when using $\mathrm{Al} / \mathrm{LiF}$ as top contact, ${ }^{6,7}$ we find that DFHCO-4T $n$-OTFTs only function properly with contacts that have a low chemical reactivity such as $\mathrm{Au}$ and $\mathrm{Ag}$, and report mobilities as high as $4.6 \mathrm{~cm}^{2} / \mathrm{V}$ s for Au topcontact transistors. We explain the reduced performance with easily oxidizable metals such as $\mathrm{Al}$ and $\mathrm{Yb}$ as a consequence of an electron-transfer reaction occurring at the metal/ DFHCO-4T interface.

The substrates used in this work are doped $n^{++}$-Si wafers with a $140 \mathrm{~nm}$ thick thermally grown $\mathrm{SiO}_{2}$ layer (serving as the OTFT gate dielectric), covered with a $5 \mathrm{~nm}$ thick poly-( $\alpha$-methylstyrene) layer ( $P \alpha \mathrm{MS}$, standard 700.000, Fluka) prepared by spin-coating a solution of 0.1 wt $\%$ $P \alpha$ MS in toluene at $4000 \mathrm{rpm}$ and drying on a hotplate at $120^{\circ} \mathrm{C}$ for $1 \mathrm{~min}^{8}{ }^{8}$ This procedure provides a high-quality, electron-trap free surface allowing excellent electron transport. ${ }^{9}$ Thin DFHCO-4T films were deposited on these substrates by thermal vacuum evaporation $\left(p=10^{-8}\right.$ torr) of the material (available from Polyera Corporation under the trade name ActivInk ${ }^{\mathrm{TM}}$ N0800), which was used as received. Atomic force microscopy analysis of DFHCO-4T reveals

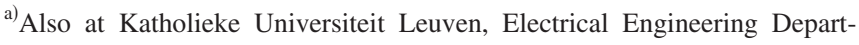
ment, B-3001 Leuven, Belgium.

${ }^{b)}$ Electronic mail: sarah.schols@imec.be.

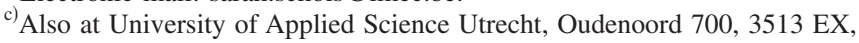
Utrecht, The Netherlands.

d) Also at Northwestern University, Department of Chemistry and the Material Research Center, Evanston, Illinois 60208, USA.
}

typical Stransky-Krastanov growth mode ${ }^{10}$ with the first few monolayers grown in a two-dimensional arrangement followed by a three-dimensional (3D) lattice. In the case of DFHCO-4T films, thick elongated needles (up to $100 \mathrm{~nm}$ long) are formed. Preliminary experiments indicated that this 3D growth can be suppressed by deposition at high substrate temperature and high deposition flux. Therefore, in this study we deposited DFHCO-4T at a flux of $4.5 \AA / \mathrm{s}$ and a substrate temperature of $70^{\circ} \mathrm{C}$. Afterwards, the transistor structure was completed by metallic top-contact $(100 \mathrm{~nm} \mathrm{Au}, \mathrm{Ag}$ or $\mathrm{Yb}$ or $0.8 \mathrm{~nm} \mathrm{LiF}$ followed by $100 \mathrm{~nm} \mathrm{Al}$ ) evaporation onto the organic semiconductor through a shadow mask. The resulting device channel width is $2000 \mu \mathrm{m}$ and the channel length varies between 50 and $200 \mu \mathrm{m}$. Immediately after their fabrication, the devices were transferred to a $\mathrm{N}_{2}$-filled glove box (without exposure to air) for electrical characterization using an Agilent 4156C parameter analyzer. Thin-film mobilities were calculated from saturation, ${ }^{11}$ using a total dielectric capacitance per area of $2.3310^{-4} \mathrm{~F} / \mathrm{m}^{2}$, which was determined based on relative dielectric constant values of 3.9 for $\mathrm{SiO}_{2}$ and 2.5 for $P \alpha \mathrm{MS}$, as obtained from capacitance-voltage measurements.

Figure 2(a) shows the output characteristics of a transistor with $130 \mu \mathrm{m}$ channel length and $\mathrm{Al} / \mathrm{LiF}$ top contacts. For this device, an apparent field-effect electron mobility of $0.03 \mathrm{~cm}^{2} / \mathrm{V} \mathrm{s}$ was calculated. This value is more than one order of magnitude lower than the electron mobility of DFHCO-4T previously reported using Au top contacts. ${ }^{5}$ In addition, the OTFTs show strongly nonideal characteristics, as apparent from a superlinear dependence of the current on the drain voltage at low bias, the saturation of the output current at a more or less fixed drain-to-source bias, and a decrease of the current at higher drain voltages. On the other hand, transistors fabricated under the same DFHCO-4T

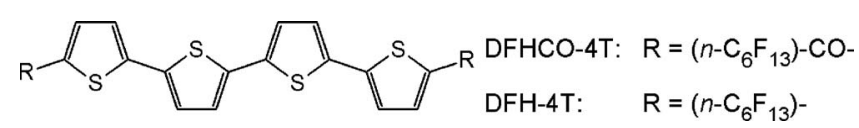

FIG. 1. Chemical structure of DFHCO-4T and DFH-4T. 
(a)
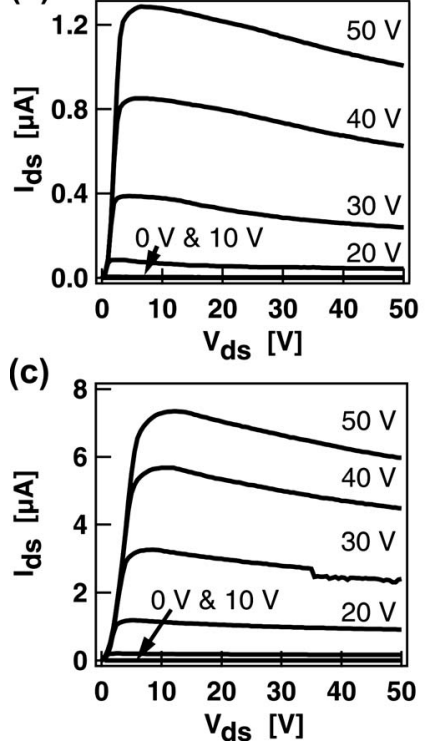

(b)

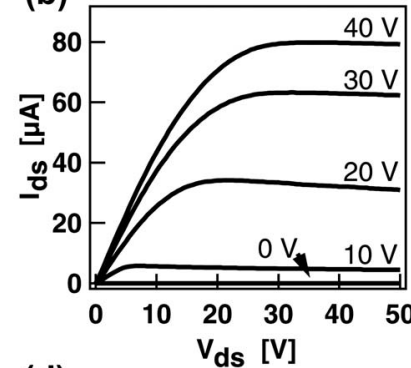

(d)

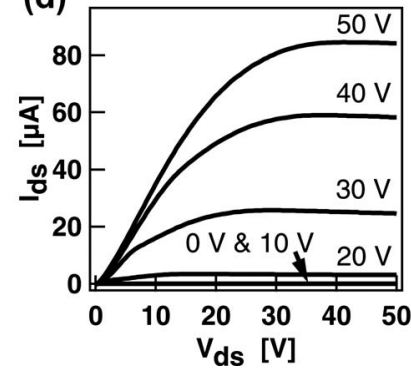

FIG. 2. Output characteristics of DFHCO-4T transistors $(W / L=2000 / 130)$ using (a) Al/LiF, (b) Au, (c) Yb, and (d) Ag top contacts.

growth conditions but with $\mathrm{Au}$ instead of $\mathrm{Al} / \mathrm{LiF}$ source-drain top contacts exhibit much better-behaved output characteristics with much higher drain currents [Fig. 2(b)]. For Au topcontact transistors with $130 \mu \mathrm{m}$ channel length, an apparent mobility of $4.6 \mathrm{~cm}^{2} / \mathrm{V} \mathrm{s}$ is measured. Such remarkable mobility achieved with Au contacts is of high technological relevance because for use in complementary logic it is preferable to use a single type of source and drain metal for both the $p$-type and the $n$-type OTFTs. The reproducibility of the results is quite good. The average apparent mobility, calculated from transistors with channel lengths between 50 and $200 \mu \mathrm{m}$ is $3.5 \mathrm{~cm}^{2} / \mathrm{V}$ s. These field-effect mobilities are higher compared to previously reported results ${ }^{5}$ and we attribute this to the different growth conditions used to deposit DFHCO-4T. The fact that electrons can be efficiently injected from $\mathrm{Au}$ into DFHCO-4T despite an injection barrier of $\sim 1 \mathrm{eV}$ is not fully understood yet. The deep lowest unoccupied molecular orbital (3.96 eV) (Ref. 12) of DFHCO-4T and the fact that in a top-contact geometry there is a high gate-field that supports the injection of charges in a large source-gate overlap area ${ }^{13}$ might be a possible explanation for this experimental observation.

The low apparent field-effect mobility (i.e., low output currents) and the nonideal characteristics of DFHCO-4T transistors with $\mathrm{Al} / \mathrm{LiF}$ top contacts compared to Au top contacts point to the presence of a current-limiting contact problem in the former. A plausible cause of this is the occurrence of a redox reaction between the $n$-type semiconductor and the Al metal contact. In fact, it is well known that ketone groups-present in the DFHCO-4T chemical structure-are easily reduced into their radical anions according to the reaction scheme shown in Fig. 3(a). ${ }^{14}$ The electron transfer reaction is driven by the oxidation of a reactive metal, as for example $\mathrm{Mg}, \mathrm{Al}, \mathrm{Fe}$, and $\mathrm{Zn}$ [depicted in Fig. 3(b) for $\mathrm{Al}]^{15,16}$ and the reduction of DFHCO-4T. The standard free energy ( $\Delta G^{\circ}$, Gibbs free energy) of the overall redox reaction depicted in Fig. 3(c) is given by Eq. (1), ${ }^{17}$ where $n$ is the overall number of electrons exchanged between the oxidizing and reducing agents for the balanced redox equation,

(a)

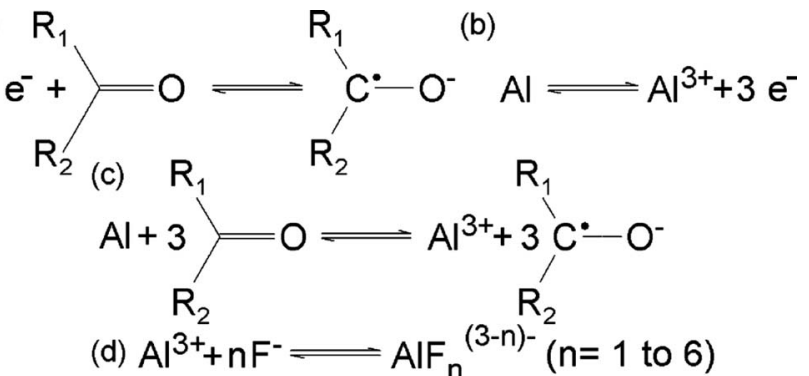

(e)

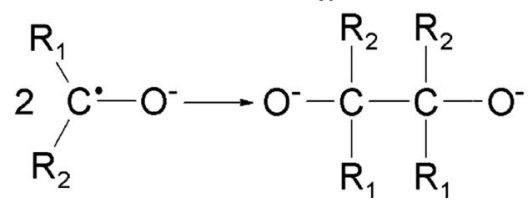

FIG. 3. (a) Reduction of a ketone, (b) oxidation of $\mathrm{Al}$, (c) redox reaction between a ketone and $\mathrm{Al}$, (d) complexation of $\mathrm{Al}^{3+}$ by $F^{-}$, and (e) dimerization of a ketone radical anion.

$F$ the Faraday constant $[96485 \mathrm{~J} /(\mathrm{V}$ mol $)]$, and $E^{\circ}$ the standard cell potential (the difference in standard electrode potentials (SEPs) of both electrochemical couples)

$$
\Delta G^{\circ}=-n F E^{\circ}
$$

For the $\mathrm{Al} / \mathrm{Al}^{3+}$ couple the SEP in aqueous solution is $-1.662 \mathrm{~V}$ versus the normal hydrogen electrode (NHE), ${ }^{18}$ which is about $-1.90 \mathrm{~V}$ versus the reference saturated calomel electrode (SCE). ${ }^{19}$ Published value for the first reduction potential of DFHCO-4T in tetrahydrofuran is $-0.88 \mathrm{~V}$ versus the SCE. $^{12}$ Inserting this potential difference into Eq. (1), with $n=3$ [Fig. 3(c)], gives $\Delta G^{\circ}=-296 \mathrm{~kJ} / \mathrm{mol}$. This indicates that the reaction between $\mathrm{Al}$ and DFHCO-4T is highly exergonic and thus thermodynamically spontaneous.

Similar reductions of organic layers by evaporation of strongly reducing metals have been reported in literature. The reaction of $\mathrm{Al}$ evaporated on films of tris(hydroxyquinoline) aluminum $\left(\mathrm{Alq}_{3}\right),{ }^{20-23}$ copper hexadecafluorophthalocyanine $\left(\mathrm{F}_{16} \mathrm{CuPC}\right){ }^{24}$ and $3,4,9,10$ perylenetetracarboxylic dianhydride (PTCDA), ${ }^{25}$ for example, were experimentally proven. The reduction of DFHCO-4T by evaporated Al [Fig. $3(\mathrm{c})]$ in our case takes furthermore advantage of some follow-up reactions. One of these reactions is the complexation of the $\mathrm{Al}^{3+}$ cation by fluoride ions $\left(F^{-}\right)$originating from an ultrathin $(0.8 \mathrm{~nm}) \mathrm{LiF}$ layer on top of the DFHCO4T. In fact, $F^{-}$anions are well known to form stable complexes $\left[\mathrm{Al}_{n}^{(3-n)+}\right.$ with $n=1-6$, Fig. $\left.3(\mathrm{~d})\right]$ with $\mathrm{Al}^{3+}$ cations. $^{26}$ Furthermore, ketone radical-anions readily dimerize affording the corresponding acyloinic species [Fig. 3(e)]. ${ }^{15}$ Such additional processes will enforce the DFHCO-4T/Al redox reaction [Fig. 3(c)] toward the right side according to Le Chatelier's principle.

The products of the reactions displayed in Figs. 3(c)-3(e), an ionic salt and possibly dimerized ketone species, will form a thin interfacial layer between the unreacted DFHCO-4T and Al layers, hindering electron injection. In the case of $\mathrm{Au}$ this kind of reaction is impossible: the SEP's of the couples involving oxidation of $\mathrm{Au}$ are so high $\left(+1.692 \mathrm{~V}\right.$ versus $\mathrm{NHE}$ for $\mathrm{Au} / \mathrm{Au}^{+}$and $+1.492 \mathrm{~V}$ versus $\mathrm{NHE}$ for $\mathrm{Au} / \mathrm{Au}^{3+}$ ) (Ref. 18) that a reaction with DFHCO-4T would be highly endergonic 
$\left(\Delta G^{\circ}=+225 \mathrm{~kJ} / \mathrm{mol}\right.$ in the case of $\mathrm{Au} / \mathrm{Au}^{+}$and $+619 \mathrm{~kJ} / \mathrm{mol}$ for $\mathrm{Au} / \mathrm{Au}^{3+}$ ).

In order to show the relevance of the ketone-group, we investigated transistors fabricated with $\mathrm{Al} / \mathrm{LiF}$ electrodes and $a, \omega$-diperfluorohexyl-quaterthiophene (DFH-4T, Fig. 1), ${ }^{4}$ an $n$-type material of similar structure, but missing the electronattracting ketone group. In this case, no significant difference in apparent electron mobilities could be observed between DFH-4T transistors with $\mathrm{Al} / \mathrm{LiF}\left(\sim 0.15 \mathrm{~cm}^{2} / \mathrm{Vs}\right)$ and $\mathrm{Au}$ $\left(\sim 0.1-0.2 \mathrm{~cm}^{2} / \mathrm{V} \mathrm{s}\right)$ (Ref. 4$)$ top contacts.

To find additional proof supporting the chemical reaction between $\mathrm{Al}$ and $\mathrm{DFHCO}-4 \mathrm{~T}$, we fabricated transistors using DFHCO-4T as the organic semiconductor but with two other top-contact metals: $\mathrm{Yb}$ and $\mathrm{Ag}$. The standard free energies for possible reactions between DFHCO-4T and $\mathrm{Yb}$ indicates that this kind of reaction is highly exergonic and thus spontaneous, independently if the $\mathrm{Yb} / \mathrm{Yb}^{2+}$ couple (SEP: $-2.76 \mathrm{~V}$ versus $\mathrm{NHE}{ }^{18}$ corresponding to $\Delta G^{\circ}=-409 \mathrm{~kJ} / \mathrm{mol}$ ) or $\mathrm{Yb} / \mathrm{Yb}^{3+}$ couple $(\mathrm{SEP}:-2.19 \mathrm{~V}$ versus NHE, ${ }^{18}$ corresponding to $\Delta G^{\circ}=-449 \mathrm{~kJ} / \mathrm{mol}$ ) is considered. The corresponding value for the reaction of DFHCO-4T with Ag (SEP: +0.7796 V versus $\mathrm{NHE}^{18}$ for $\left.\mathrm{Ag} / \mathrm{Ag}^{+}\right)$is $+139 \mathrm{~kJ} / \mathrm{mol}$, indicating that this reaction is impossible. The output characteristics of $\mathrm{Yb}$ and $\mathrm{Ag}$ top-contact transistors with $130 \mu \mathrm{m}$ channel length are shown in Figs. 2(c) and 2(d). Transistors with Yb top contacts show similar output characteristics and low apparent field-effect mobility $\left(0.06 \mathrm{~cm}^{2} / \mathrm{Vs}\right)$ as $\mathrm{Al} / \mathrm{LiF}$ transistors, whereas the output characteristics of $\mathrm{Ag}$ top-contact transistors are much better. When Ag is used as top metal contact an apparent mobility of $1.7 \mathrm{~cm}^{2} / \mathrm{Vs}$ was measured. These results are in agreement with our argumentation and give further evidence that a redox reaction occurs at the interface between DFHCO-4T and easily oxidizable metals, similar to Hirose et al.'s report that PTCDA reacts with $\mathrm{Al}$, but not with $\mathrm{Au}$ and $\mathrm{Ag}$. ${ }^{25}$

In summary, DFHCO-4T transistors with $\mathrm{Au}$ top contacts exhibit an average apparent field-effect electron mobility of $3.5 \mathrm{~cm}^{2} / \mathrm{Vs}$, whereas the mobility of similar transistors fabricated with easily oxidizable top-contact metals is far lower. The reduced transistor performance of $\mathrm{Al} / \mathrm{LiF}$ and $\mathrm{Yb}$ top-contact transistors is attributed to an electron-transfer reaction between the ketone group(s) of DFHCO-4T and $\mathrm{Al}$ or $\mathrm{Yb}$, respectively, leading to an insulating interfacial layer. Since $\mathrm{Au}$ and $\mathrm{Ag}-$ in contrast to $\mathrm{Al}$ and $\mathrm{Yb}$-do not react with the semiconducting material, the use of these inert metals is beneficial to achieve high-performance DFHCO-4T-based $n$-OTFTs.
This work is supported by the EU-funded Project OLAS (Contract No. 015034). S. Schols acknowledges the FWO Vlaanderen for financial support.

${ }^{1}$ P. H. Wöbkenberg, J. Ball, D. D. C. Bradley, T. D. Anthopoulos, F. Kooistra, J. C. Hummelen, and D. M. de Leeuw, Appl. Phys. Lett. 92, 143310 (2008).

${ }^{2}$ H. E. Katz, A. J. Lovinger, J. Johnson, C. Kloc, T. Siegrist, W. Li, Y.-Y. Lin, and A. Dodabalapur, Nature (London) 404, 478 (2000).

${ }^{3}$ P. R. L. Malenfant, C. D. Dimitrakopoulos, J. D. Gelorme, L. L. Kosbar, T. O. Graham, A. Curioni, and W. Andreoni, Appl. Phys. Lett. 80, 2517 (2002)

${ }^{4}$ A. Facchetti, M. Mushrush, M. Yoon, G. R. Hutchison, M. A. Ratner, and T. J. Marks, J. Am. Chem. Soc. 126, 13859 (2004).

${ }^{5}$ M. Yoon, C. Kim, A. Facchetti, and T. J. Marks, J. Am. Chem. Soc. 128, 12851 (2006).

${ }^{6}$ D. J. Gundlach, K. P. Pernstich, G. Wilckens, M. Grüter, S. Haas, and B. Batlogg, J. Appl. Phys. 98, 064502 (2005).

${ }^{7}$ T. D. Anthopoulos, B. Singh, N. Marjanovic, N. S. Sariciftci, A. M. Ramil, H. Sitter, M. Cölle, and D. M. de Leeuw, Appl. Phys. Lett. 89, 213504 (2006).

${ }^{8}$ K. Myny, S. De Vusser, S. Steudel, D. Janssen, R. Müller, S. De Jonge, S. Verlaak, J. Genoe, and P. Heremans, Appl. Phys. Lett. 88, 222103 (2006).

${ }^{9}$ L. Chua, J. Zaumseil, J. Chang, E. C. Ou, P. K. Ho, H. Sirringhaus, and R. H. Friend, Nature (London) 434, 194 (2005).

${ }^{10}$ J. A. Venables, G. D. Spiller, and M. Hanbucken, Rep. Prog. Phys. 47, 399 (1984).

${ }^{11}$ J. Zaumseil and H. Sirringhaus, Chem. Rev. 107, 1296 (2007).

${ }^{12}$ M. Yoon, S. A. DiBenedetto, A. Facchetti, and T. J. Marks, J. Am. Chem. Soc. 127, 1348 (2005).

${ }^{13}$ J. Zaumseil, C. L. Donley, J. Kim, R. H. Friend, and H. Sirringhaus, Adv. Mater. (Weinheim, Ger.) 18, 2708 (2006).

${ }^{14} \mathrm{~J}$. Grimshaw, Organic Electrochemistry: An Introduction and a Guide, 4th ed. (Carbonyl Compounds, New York, 2000), Chap. 10, pp. 411-434.

${ }^{15}$ H. G. O. Becker, R. Beckert, G. Domschke, E. Fanghänel, W. D. Habicher, P. Metz, D. Pavel, and K. Schwetlick, Organikum, 21st ed. (Wiley, Weinheim, 2001), Chap. D.7, pp. 586-587.

${ }^{16}$ M. Hulce and T. Lavaute, Tetrahedron Lett. 29, 525 (1988).

${ }^{17}$ J. C. Kotz and K. F. Purcell, Chemistry and Chemical Reactivity, 2nd ed. (Saunders, Philadelphia, 1991), Chap. 21, pp. 851-899.

${ }^{18}$ CRC Handbook of Chemistry and Physics, 85 th ed., edited by D. R. Lide (CRC, Boca Raton, 2004), pp. 8.23-8.33.

${ }^{19}$ A. J. Bard and L. R. Faulkner, Electrochemical Methods: Fundamentals and Applications, 2nd ed. (Wiley, New York, 2001), p. 809.

${ }^{20}$ Q. T. Le, L. Yan, Y. Gao, M. G. Mason, D. J. Giesen, and C. W. Tang, J. Appl. Phys. 87, 375 (2000).

${ }^{21}$ M. G. Mason, C. W. Tang, L. S. Hung, P. Raychaudhuri, J. Madathil, D. J. Giesen, L. Yan, Q. T. Le, Y. Gao, S. T. Lee, L. S. Liao, L. F. Cheng, W. R. Salaneck, D. A. dos Santos, and J. L. Brédas, J. Appl. Phys. 89, 2756 (2001)

${ }^{22}$ C.-I. Wu, G.-R. Lee, and T.-W. Pi, Appl. Phys. Lett. 87, 212108 (2005).

${ }^{23}$ C. Shen, A. Kahn, and J. Schwartz, J. Appl. Phys. 89, 449 (2001).

${ }^{24}$ C. Cheng, A. Kahn, and J. Schwartz, J. Appl. Phys. 90, 6536 (2001).

${ }^{25}$ Y. Hirose, A. Kahn, V. Aristov, P. Soukiassian, V. Bulovic, and S. R Forrest, Phys. Rev. B 54, 13748 (1996).

${ }^{26}$ M. S. Corbillon, M. A. Olazabal, and J. M. Madariaga, J. Solution Chem. 37, 567 (2008). 